\title{
A successful case of emergency landslide response - the Sept. 2, 2014, Shanshucao landslide, Three Gorges Reservoir, China
}

\author{
Bolin Huang ${ }^{1 *}$, Wangjun Zheng ${ }^{2}$, Zuzhan $\mathrm{Yu}^{2}$ and Guangning Liu ${ }^{1}$
}

\begin{abstract}
Background: The Shanshucao landslide is a bedding landslide in the Three Gorges Reservoir. This landslide had not been subject to obvious deformation in the past, nor had it been included in the list of geologic hazards previously identified in the Three Gorges Reservoir.

Findings: The Shanshucao slope failed at 13:19 p.m. on Sep. 2, 2014, during which the northern soil mass slid rotationally on a plane under traction produced by the rocky bedding landslide to the south. The Daling Hydropower Station was situated on the Shanshucao landslide, and power generation pipelines feeding the station began leaking four hours before the incident. Heavy rainfall, fluctuation of water level in the reservoir, and leakage of tunnel pipelines caused a sharp increase of hydraulic uplift pressure within the slope. This was the key trigger of the incident.

Conclusion: Before the incident, members of the public reported timely clues on slope deformation, and landslide specialists and governmental officials made prompt collaborative decisions that contributed to a successful emergency evacuation of the landslide site. As a consequence, all residents living on the slope evacuated successfully before the occurred. This successful case of emergency landslide evacuation provides guidance for dealing with unexpected geologic hazards in the Three Gorges Reservoir, and in other disaster-prone regions world-wide.
\end{abstract}

Keywords: Three Gorges Reservoir; Shanshucao landslide; Bedding landslide; Water uplift pressure; Emergency evacuation

\section{Findings}

Emergency survey show that the Shanshucao landslide is a bedding landslide, the northern soil mass slipped rotationally on a plane under traction produced by the rocky bedding landslide to the south. Heavy rainfall, raise of water level in the reservoir, and leakage of tunnel pipelines inside the slope caused a sharp increase of hydraulic uplift pressure within the slope. This was the key trigger of the landslide. Members of the public reported timely clues on slope deformation, and landslide specialists and governmental officials made prompt collaborative decisions that contributed to a successful emergency

\footnotetext{
* Correspondence: bolinhuang@aliyun.com

'Wuhan Centre of China Geological Survey, Wuhan 430205, China Full list of author information is available at the end of the article
}

evacuation of this landslide. The MEWNG shows its powerful ability to deal with emergency landslide.

\section{Introduction}

The Three Gorges Project stands as the largest hydropower engineering in the world, Since the 1950s, when experts first argued for its development, extensive efforts have been made on investigation, survey, prevention, and control of geologic hazards. The geohazards in the Three Gorges Reservoir are characterized by their extensive distibution, considerable influence, and high activity. To combat these features, the Three Gorges Reservoir has seen the establishment of a monitoring and early warning network of geohazards known as MEWNG. This network is composed of observations from the local people, an established preparedness system, a professional monitoring system, and an information management and early warning command 
system (Li 2000, 2002). This network effectively combines the efforts of the local people, geohazard specialists, and governmental officials. Slope information collected from periodic monitoring is reported to the specialists by the local populace, providing clues to work efficiently, and to draw firmly-based conclusions. Government officials then make decisions based on this information. This system radically broadens the vision of the geohazard specialists, and increases the scientific basis of government emergency response decisions. The MEWNG has been shown to be effective in dealing with unexpected landslides, as demonstrated by previous examples in the Xintan landslide and the Wangxia rockfall (Luo 1986, Wang 1996, Le et al. 2011).

The Shanshucao slope is located in Zigui County in Three Gorges Reservoir. It is a newborn bedding landslide, which failed on Sep. 2, 2014. This landslide has aroused considerable concern, as it destroyed a small local hydropower station. This was the first instance of significant damage to a hydropower station in the Three Gorges Reservoir from landslide. Fortunately, no casualties or injuries occurred, due to prompt evacuation before the failure. This was a successful case of geohazard emergency response in the Three Gorges Reservoir, facilitated by the MEWNG system. This paper describes the landslide process, the triggering factors involved, and the successful operation of MEWNG, providing guidance for emergency responses to unexpected geohazards in the Three Gorges Reservoir, and in other regions around the world.

\section{An overview of the Shanshucao slope}

The Shanshucao slope is located in Shazhenxi Town, on the left bank of the Luogudong River, a tributary of the Qinggan River in the Three Gorges Reservoir (Fig. 1). The landslide is only $300 \mathrm{~m}$ away from Shazhenxi Town. The Qianjiangping slope, which is situated along the Qinggan River, lies on the northwest of the Shanshucao slope.
The Shanshucao slope is situated downstream of Daling Village, and can be divided into two parts according to the composition of its shallow materials. The southern part is composed primarily of bedded bedrock, whereas the northern is covered by a $1-10 \mathrm{~m}$ thickness of soil. Lithologically, the bedrock belongs to the Niejiashan Formation of Jurassic Age $\left(\mathrm{J}_{2} \mathrm{n}\right)$, which consists mainly of greyish-green thickly-bedded sandstones in its upper part, and purple to red medium-bedded sandstones interbedded with silty mudstones in its lower part. In this area the Niejiashan Formation has a strike of $115^{\circ}$ and a dip of $20^{\circ}$. The soil mass is composed mostly of eluvium consisting of sandstone gravels. With a bedding structure, the slope aspect is $105^{\circ}$, and the average slope angle is $21^{\circ}$, similar to the dip of the bedrock. Vegetation is extensively developed on the slope. The rocky slope is mainly covered by cedar trees, whereas the soil slope is occupied by citrus trees. A small platform is present at an elevation of $300 \mathrm{~m}$. The top of the slope lies at an elevation of $425 \mathrm{~m}$, where it forms a divide between the Qinggan and Luogudong Rivers.

As shown in Fig. 2, National Road G348 passes the slope area. This is the nearest traffic artery connecting Yichang City to Shazhenxi Town and Badong County. More importantly, a small hydropower station named the Daling Hydropower Station was situated within the slope area. The Daling Hydropower Station was a diversion hydropower station with an installed capacity of 1,000 KW, and was built in 2008. The main buildings of the hydropower station lay the slope, along with a 5-storey dormitory, a $300 \mathrm{~m}^{2}$ workshop, pressure pipes, and an impounding forebay. More than 20 people were resident at the hydropower station. Water used by the hydropower station was sourced from an upstream gully, and was derived from the Luogudong River. The water was delivered by tunnel pipelines, and flowed through the Daling slope before reaching the impounding forebay on the Shanshucao

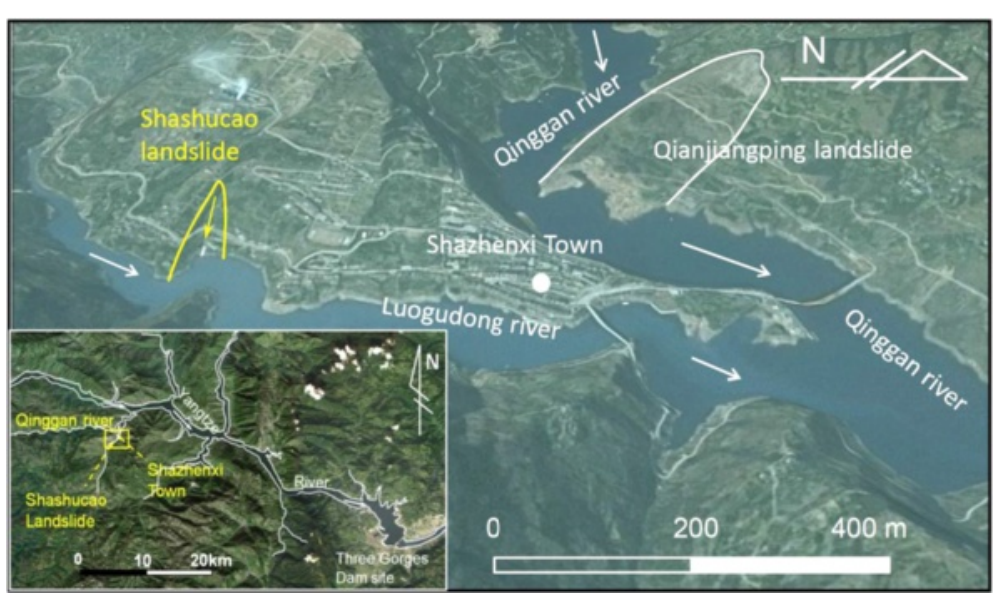

Fig. 1 Location map of the Shanshucao slope. Inset shows the relative location between the Shanshucao landslide and the Three Gorges Dam 


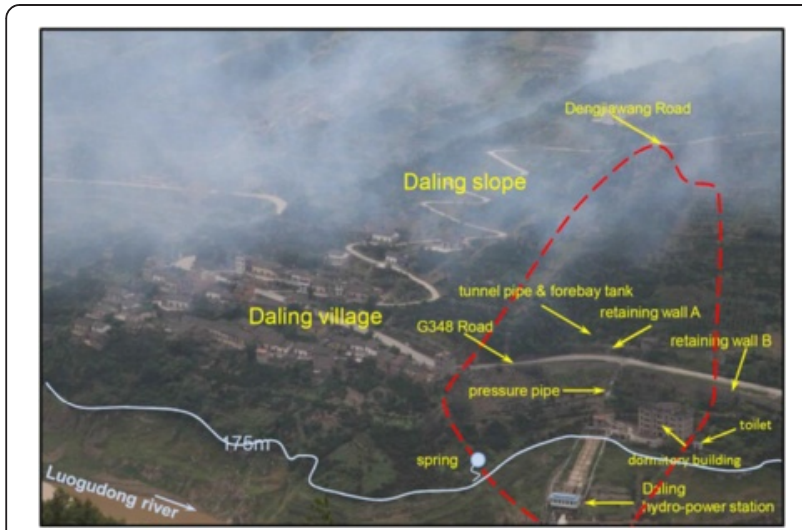

Fig. 2 Aerial view of the Shanshucao slope before failure (taken in July, 2014). Red dotted lines delineate the extent of the landslide

slope, from which it was pumped into the pressure pipes for power generation.

As specified in relevant Chinese laws, prudent site selection and environmental impact assessment must be conducted prior to commencing construction of any hydropower station. Site selection and subsequent construction of the Daling Hydropower Station therefore meant it was recognized as stable by many experts. Consequently, this slope was not included in the database of local geohazards, as it was assumed to be safe. Although there had been no visible deformation in the Shanshucao slope in the past, the orientation of the Shanshucao slope and dip of the basement offered potential for structural sliding. This slope could thus be regarded as an overlooked potential landslide. This potential was realized by the Shanshucao landslide, which occurred quite suddenly at 13:19 p.m. on Sept. 2, 2014.

\section{Landslide process \& emergency disposal process}

The forebay channels in the Daling Hydropower Station started to seep at about 9:00 a.m. on Sep. 2, 2014, and the pressure pipes cracked and leaked. However, no deformation was observed on the ground nearby at that time. The head of the hydropower station immediately contacted the chief engineer (one of the authors of this paper) of geological hazards in the Land and Resources Bureau of Zigui County to seek professional assistance, hoping the cause of the leakage could be established. At around 12:30 a.m., the chief engineer carried out an initial investigation of the channel seepage and pipe leakage, accompanied by officials from the Shazhenxi Government. During this investigation, the leakage increased abruptly, changing from seeping to jetting (Fig. 3). This change suggested that the pressure pipes had deformed more seriously, resulting in larger cracks. Meanwhile, a considerable volume of underground water flowed out in the upstream reaches, at an elevation of $180 \mathrm{~m}$ a.s.l. (the spring shown in Fig. 2,), with a flow diameter of $12 \mathrm{~cm}$, and a high flow rate. At this stage, no

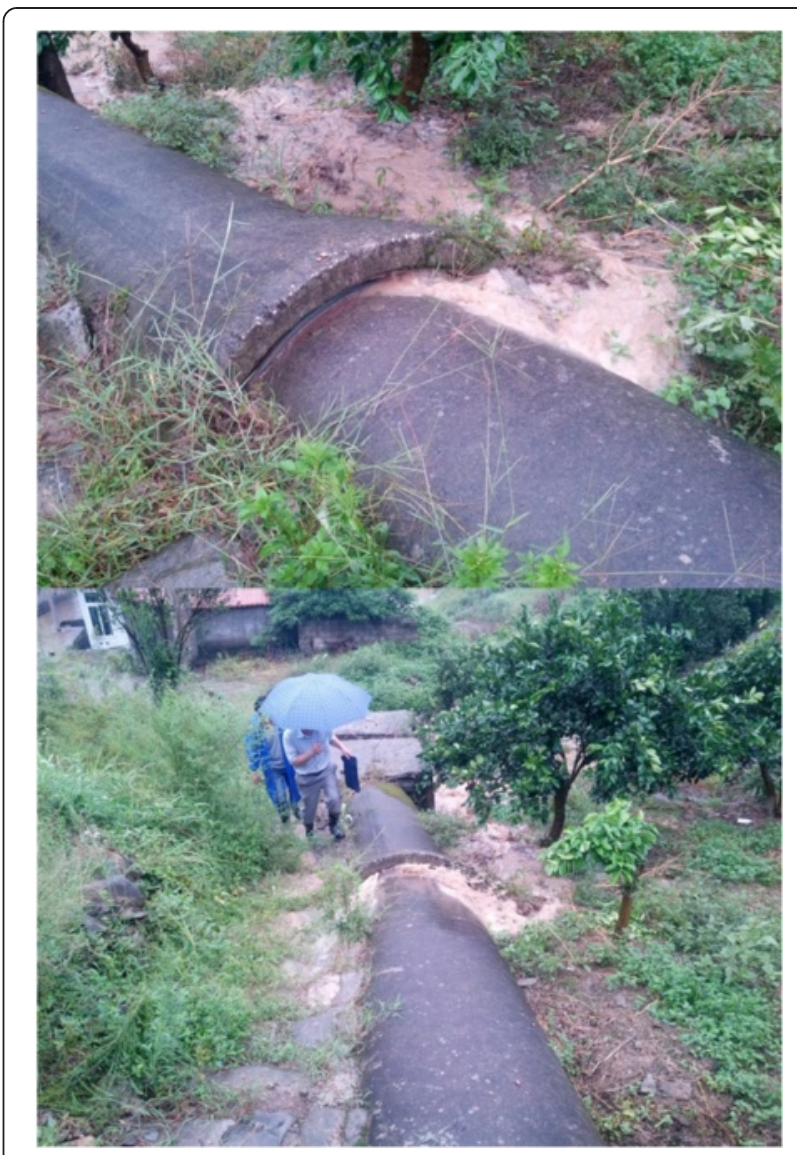

Fig. 3 Photographs of leakagess from the pressure pipes. The up photo was taken at 12:53 p.m., when only one side was leaking a small amount of water. The photograph at end was taken at 12:59 p.m., when the pipes were leaking a significant volume of water on both sides

visible deformation had been observed on the slope nearby the pressure pipes, or on National Highway G348.

At around 13:05 p.m., it was concluded from preliminary investigation that the forebay and tunnel pipelines had been destroyed by deformation of the slope, resulting in penetration of a considerable volume of water into the slope; this water then seeped through rock mass fissures. Intensified deformation and abrupt outflow of underground water suggested that the slope was actively deforming. At that time, more and more visible fractures appeared in the south side of the Highway G348, and the northern road began to bulge intactly, indicating that global deformation as occurring. In light of the requirements of the MEWNG in the Three Gorges Reservoir, and after discussion with the geological engineers on-site, the heads of the Shazhenxi Government took the following emergency measures: 1) immediate shut-down of the far-end (uphill) water pumping system to cut off the water flow into the slope; 2) informed the power supply authorities to suspend power supply, to prevent risks associated with 
destruction of the hydropower station; 3) classify alert zones based on geomorphic conditions, and assign the incident with an orange alert level (inferior only to the red alert level represented by intense deformation); 4) promptly organize all the residents to evacuate from the area, and close all relevant roads in the area; 5) dispatch two technical groups to conduct emergency investigations and to delineate the extent of the landslide: one group was responsible for observing deformation on the lateral margin along Highway G348, while the other was sent to observe deformation of the upper slope along the Dengjiawang Road and at higher elevation, to locate the head of the landslide.

As instructed by the above emergency response plan, the Daling Hydropower Station staff, nearby residents, and the students and staff of Shazhenxi Middle School all evacuated promptly from the alert zone (Fig. 4). Thanks to the effectiveness of previous emergency evacuation drills in the case of geohazards, all 524 students and staff from the school had evacuated within $5 \mathrm{~min}$. A total of over 950 persons had evacuated the classified alert zone within 15 min of the evacuation instruction being issued.

At 13:19 a.m., the slope slid rapidly as a whole. At this time, the technicians dispatched to the peak were still on the Daling slope, but had not arrived at the head of the landslide, and fortunately they escaped injury. The Shanshucao slope slid for approximately 2 min or so, with a loud crash and emission of a cloud of dust. Sporadic rockfalls were observed at the lateral margin and trailing edge of the slope following the main sliding.

After the landslide, a prompt emergency investigation was organized to determine whether the landslide would tend to expand, and movement resume. Meanwhile, the governmental officials sent relevant personnel to check whether there was anyone had been injured or killed by the landslide. By 14:15 p.m., the officials had ascertained that there had been no injuries or fatalities, and they then adjusted the landslide alert level to red. Under a red alert, the landslide is regarded as being under intense deformation, landslide hazard could threat to the safety of life and property around the immediate area of the slide in the next 24 hours, and crowd and traffic control should be carried out for at least the next 24 hours. At 14:16 p.m., the chief engineer reported this landslide incident to superiors in the technical management agency, the Bureau of Land Resources of Yichang City, and the Geo-Hazard Command Center of the Three Gorges Reservoir, and also requested additional technical support. A fully-automated displacement monitor was then installed to perform monitoring on the landslide mass and its surrounding areas. In the meantime, many experts rushed to the site to examine deformation of the landslide. At this stage, the professional monitoring and consultation phase of the landslide had begun.

\section{Losses associated with the landslide}

Figure 5 shows a panoramic view of the Shanshucao slope after the collapse. The landslide had destroyed the entire Daling Hydropower Station, including three buildings and workshops, along with various pipelines. The forebay, powerhouse, and the transmission and supply equipment were all destroyed or buried. National Road G348 was cut, and a $200 \mathrm{~m}$ long segment destroyed, along with a $450 \mathrm{~m}$ length of village and town roads. A 20 hectares citrus orchard was damaged to varying extent, of which 4.05 hectares were completely destroyed. The supply lines of 3 power supply sub-stations were damaged, 27 utility poles were destroyed, and some

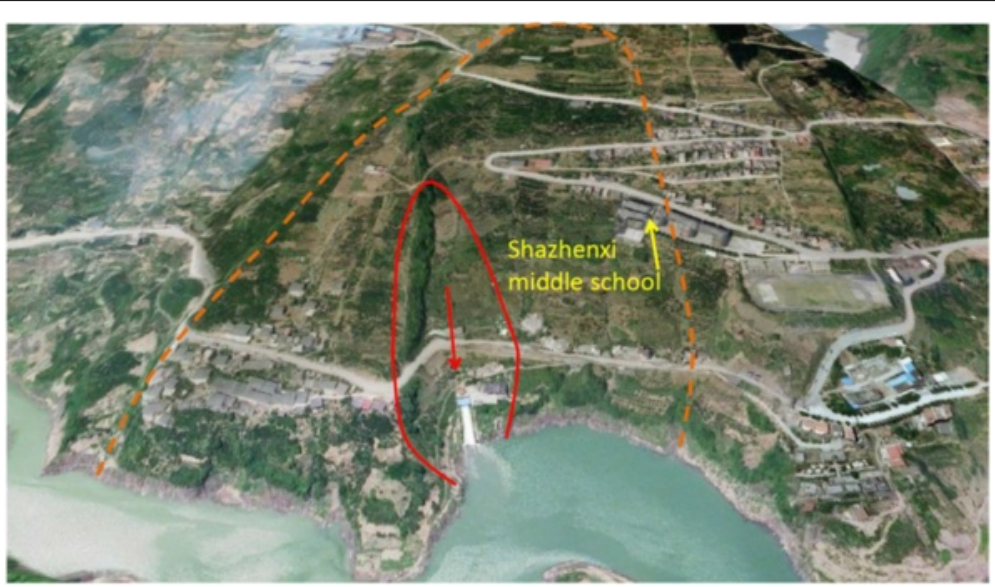

Fig. 4 Alert zones defined in the emergency response. The red lines delineate the actual extent of the landslide range, and the dotted orange lines delineate the alert zones before the collapse. No residents live on the opposite bank of the Luogudong River, and that hence that area is excluded from the alert zone 


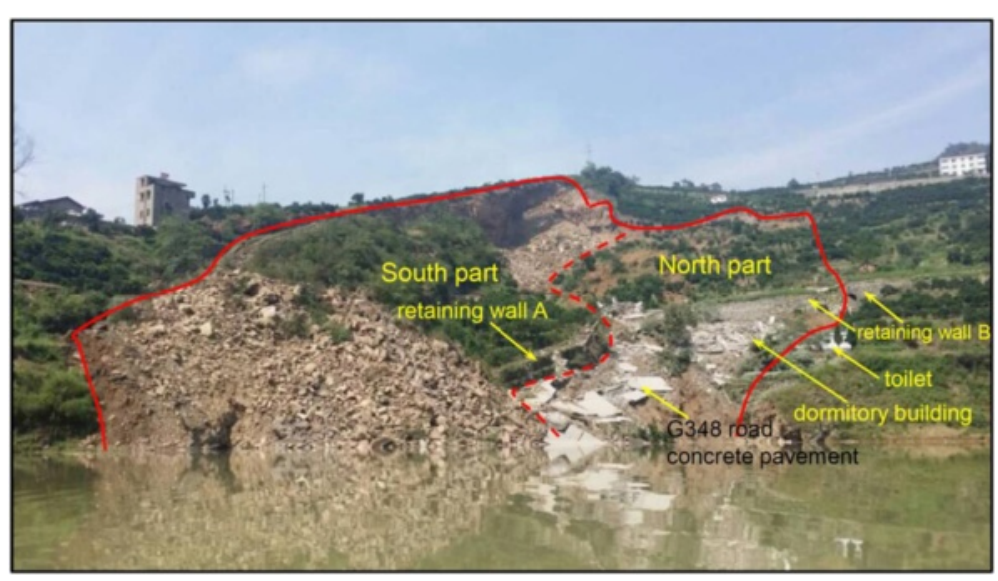

Fig. 5 Panoramic view of the Shanshucao slope after failure (taken on Sept. 4). No remanents of the hydropower station can be seen in the ruins

3,500 $\mathrm{m}$ of wires damaged. The direct economic losses are estimated to be 5.19 million US dollars.

\section{Landslide features}

An intensive field survey was conducted after Shanshucao slope failed. The elevation of the head of the landslide was $285 \mathrm{~m}$, the toe of the suface of rupture of the landslide lay at an elevation of $180 \mathrm{~m}$, and the toe of the landslide slid into the Luogudong River. The elevation of the water level on the day of the landslide was $162.3 \mathrm{~m}$ a.s.l. The area of the bedrock slide zone was $15,500 \mathrm{~m}^{2}$, and that of the soil mass slide zone $9,300 \mathrm{~m}^{2}$, giving a total area of the landslide of almost $25,000 \mathrm{~m}^{2}$. The form of the landslide was tongue-shaped, with a length of about $350 \mathrm{~m}$ and width of 80-120 m (Fig. 6). The soil mass slide zone had a thickness of $1-10 \mathrm{~m}$, averaging $5 \mathrm{~m}$. Based on the height

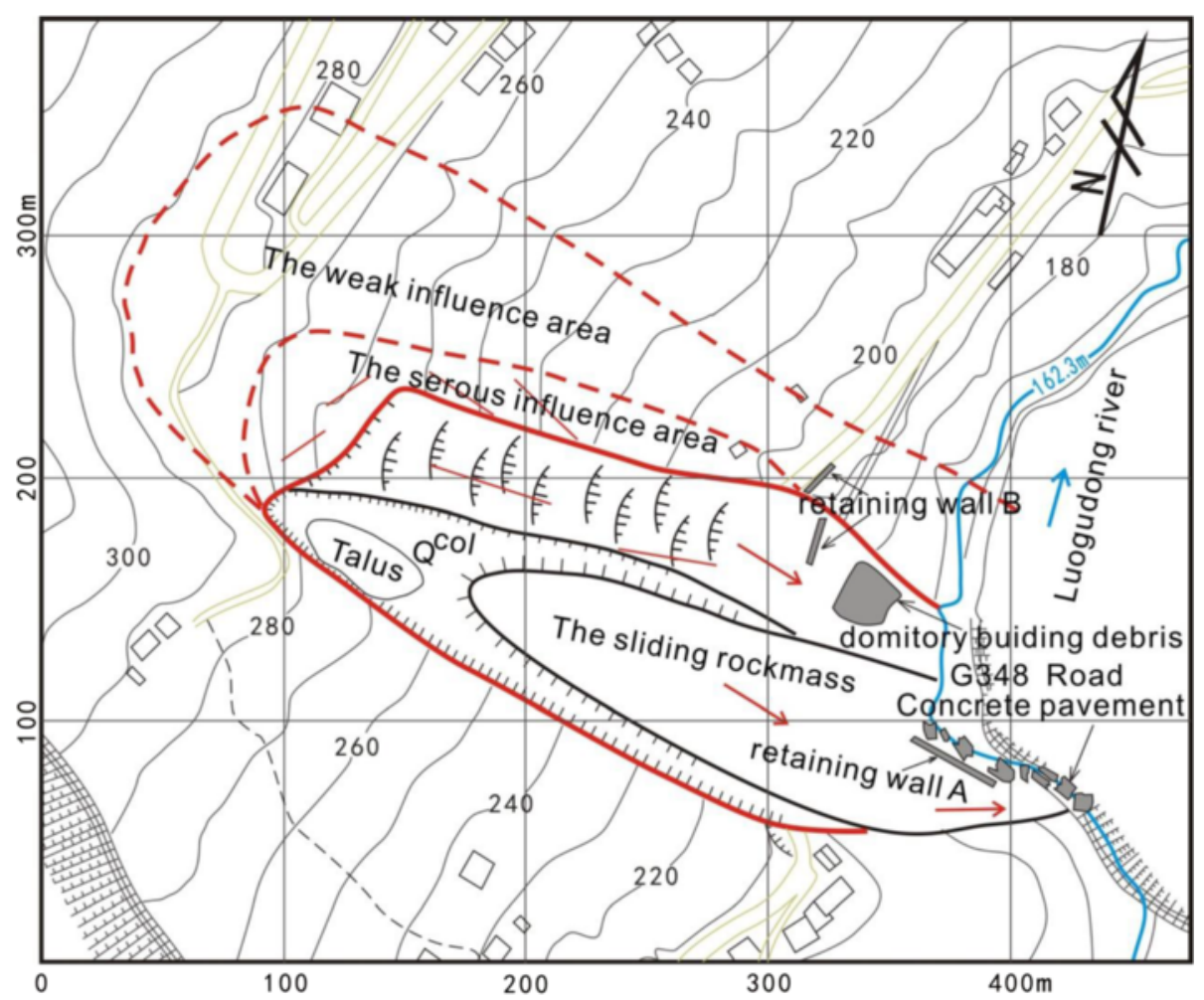

Fig. 6 Sketch map of the Shanshucao landslide. Toothed lines are the landslide cliff, the red lines are major cracks, and the dashed red lines are the range of the influence area 


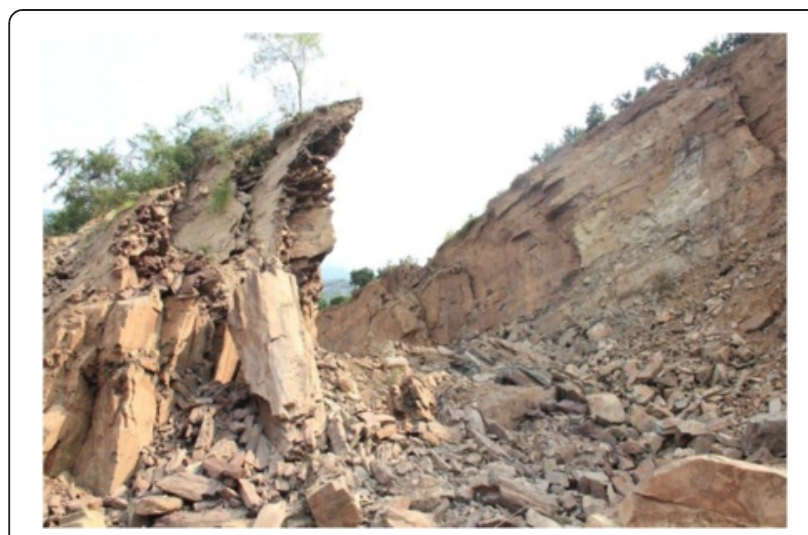

Fig. 7 Photograph of the crack trough between the rocky slide mass and the southern flank cliff

difference of the flank cliff, the thickness of the rocky slide zone is calculated to be $25-30 \mathrm{~m}$. Therefore, it is estimated that the volume of the landslide was about $465,000 \mathrm{~m}^{3}$.

The slide of the rocky mass caused the formation of tension cracks around the rocky slide mass (Fig. 7). The width of the southern flank crack is about $12-23 \mathrm{~m}$, with a length of $260 \mathrm{~m}$, and is approximately U-shaped. A large number of rock blocks accumulated in its bottom part. The tension crack between the rocky slide mass and the soil mass is V-shaped, and has an average width of 1-3 m (Fig. 8). According to presence of G348 road debris and the position of the crown crack, the sliding distance of the rocky mass was about $117 \mathrm{~m}$. The sliding distance of the soil mass decreases as it extends to the north. On the northern boundary of the landslide, retaining wall $\mathrm{B}$ was cut into two parts, with a horizontal displacement of $11.9 \mathrm{~m}$, and a vertical displacement of $3.5 \mathrm{~m}$ (Fig. 6).

The general sliding direction of the Shanshucao landslide was about $105^{\circ}$. Because of the blockage of ridge, the direction of the rocky slide mass shifted from $105^{\circ}$ to $75^{\circ}$ around the zone of the foot (Fig. 10). According to the observed

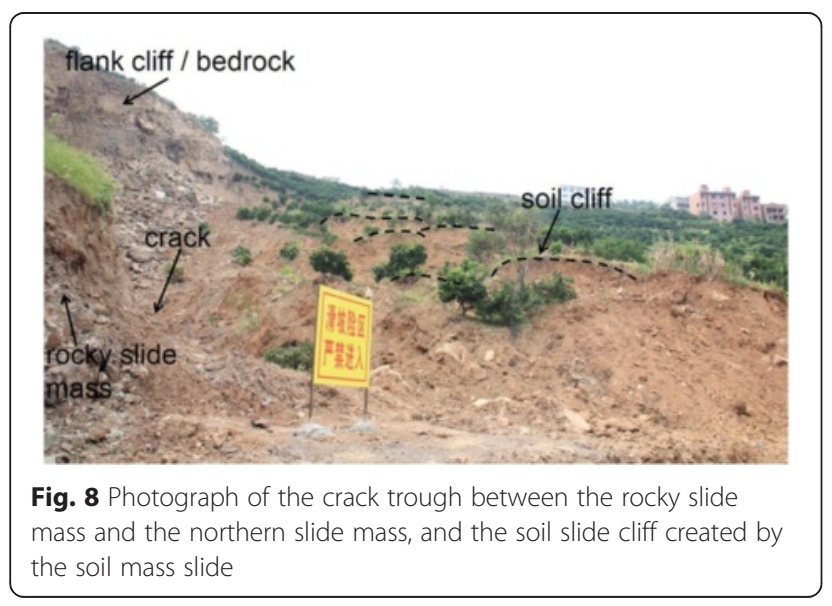

slide time of about 2 minutes and the maximum sliding distance of about $117 \mathrm{~m}$, based on Newton's Laws of Motion it can be simply estimated that the maximum speed of movement of the rocky landslide was about $2 \mathrm{~m} / \mathrm{s}$.

The rocky sliding mass exhibits the representative characteristics of translational slide, such as an intact slide mass and wide tension cracks. The structure interbeded soft and hard layers is also prone to translational sliding. The soil cliff and the reduction of sliding distance in the soil mass part of the slide shows that the soil mass was drawn to slide by the lateral traction of the rocky sliding mass. The translational slide of the rocky mass led the lateral soil mass to rotationally slide on the surface of rupture. According to subsequent detailed surveys, the lithology of the rocky sliding zone was brittle and thinly-bedded silty mudstone, which is also very smooth to the touch (Fig. 9). The surface of the rupture of the soil mass is sandstone, which also crops out immediately adjacent to the landslide (Fig. 10).

\section{Trigger mechanism of the landslide}

As the northern soil mass was drawn by the traction of the southern rocky sliding mass, only the trigger mechanism of the southern rocky mass is discussed here.

Water level fluctuation in the toe of the landslide produced by regulation of the Three Gorges Reservoir was naturally considered to be the trigger of the landslide. Due to onset of the seasonal autumn floods, water level in the reservoir fluctuates significantly. Fig. 11 shows the changes in water level over the period from Aug. 13, 2014 to Sep. 13, 2014. Water level rose by $3.8 \mathrm{~m}$ between 8:00 am, Sep. 1 and 8:00 am, Sep. 2 . A rise of this magnitude is unprecedented. The failure was probably triggered by the direct reduction in normal load within the toe of the slope and dynamic hydraulic pressure of underground water caused by the rising water level (Wang et al. 2004, Singh et al. 2012).

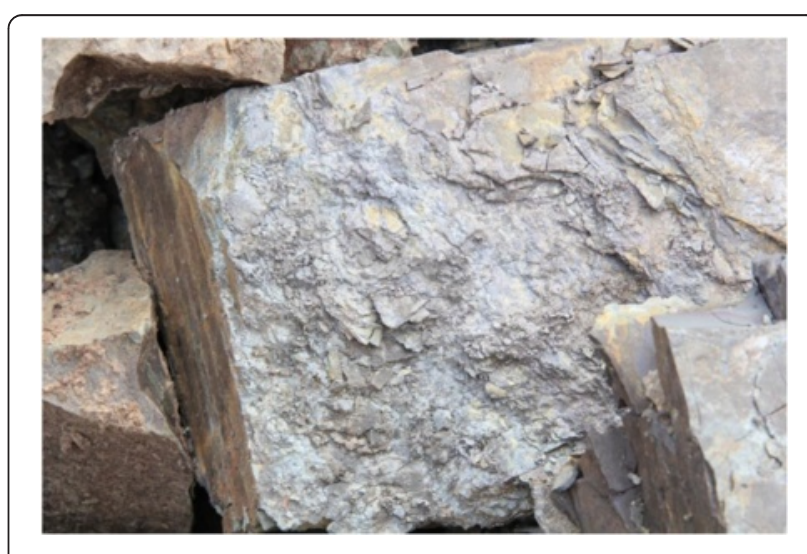

Fig. 9 Photograph of the silty mudstone of the potential slide surface 


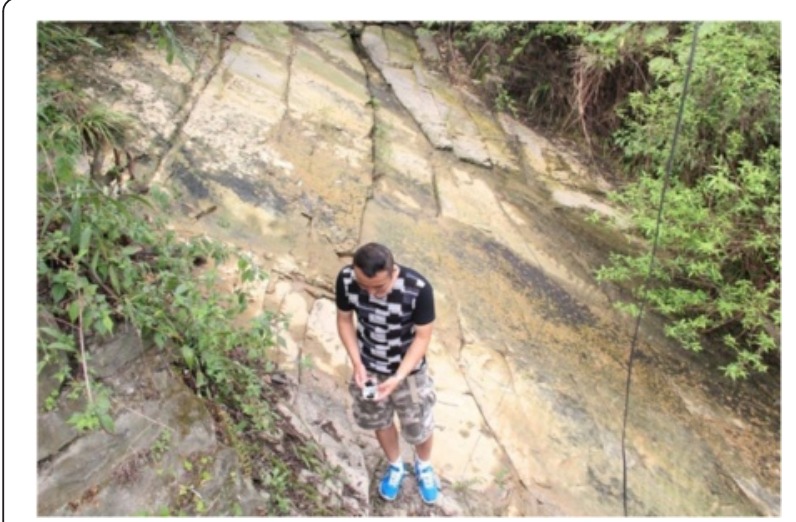

Fig. 10 Weathered surface of the preexisting sandstone layer, $20 \mathrm{~m}$ from the northern boundary of the landslide

Precipitation is monitored in Shazhenxi Town. Intense rain fell from Aug. 27 to Sept. 2, and maximum rainfall occurred on Sep. 2, with a 24 hour fall of $96.5 \mathrm{~mm}$ (Fig. 12). Intense rain may saturate the sliding mass, increase its unit weight, and decrease its strength ( $\mathrm{He}$ et al. 2009, Miller et al. 2009). More importantly in this case, torrential rain may generate dynamic hydraulic pressure, which would reduce the anti-slide force, and increase the slide force.

The toe of the Shashucao slope had been eroded by the Luogudong River long ago, and hence offered little resistance to sliding. The results of field survey showed that in addition to four sets of short fresh fracture surfaces in the southern flank boundary of the landslide, the structural surface of the cliff is brown, and weathering discoloration and clay adhered to most of the surface (Fig. 13). This shows that this flank structural surface was pre-existing. The lateral boundary offered friction and some tension resistance from the limited residual rock bridge on the south side, and the soil adjacent to the rock mass on the north side. However, these resistances were limited.

Under the conditions of intense rain and rapid rise of the water level, the Shashucao landslide began to deform slowly. In this case, if there had been no pressure pipe on

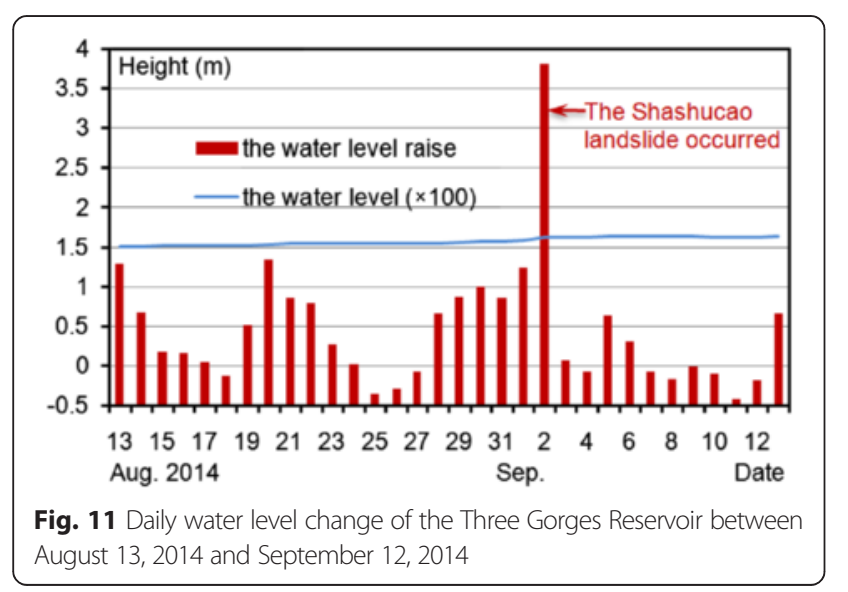

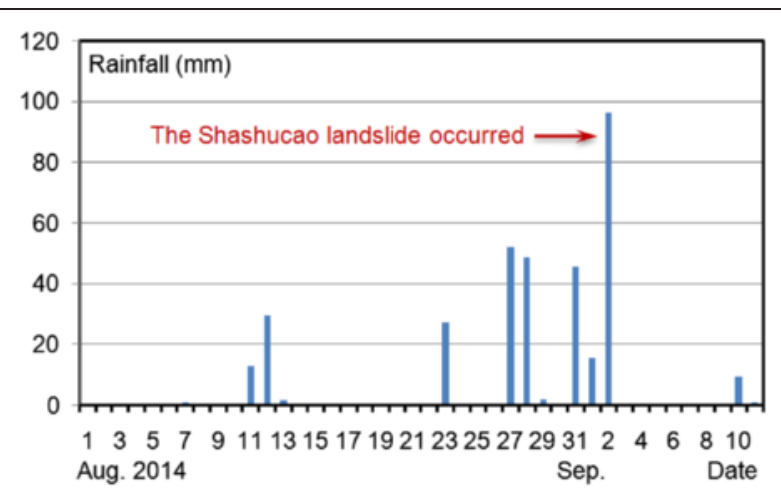

Fig. 12 Precipitation recorded at Shazhenxi Town between August 1st, 2014 and September 10, 2014

the Shashucao slope, the slide perhaps may not have occurred. Gentle deformation of the slope would have generated deformation of the structure inside the slope. This is the reason why the forebay and tunnel pipelines deformed. Once water began to leak leaking from these structures, a large volume of water could enter the mass, leading to the great changes of groundwater and forces within the landslide mass. The water originally used for power generation had a high head of pressure and large flow. When entering into sliding surface through the fissure network, the water generated high groundwater uplift pressure on the bottom of the surface of rupture, and finally initiated the rapid sliding of the slope (Fan et al. 2009, Brönnimann 2011).

The mechanical model for the translational landslide with intact rocky mass can be simplified as a two-dimensional longitudinal section, as shown in Fig.14a. The situation of the landslide after failure is sketched in Fig. 14b.

\section{Discussion}

Only several hours elapsed between the appearance of visible deformation of the Shanshucao slope to the official decision to evacuate. The rapid increase of the displacement of the fissure on Highway G348 road was the main reason which led to the prompt official decision. Although the detailed boundary of the landslide was not clear at that stage, the displacement became more larger and larger in a very short time, which showed that the

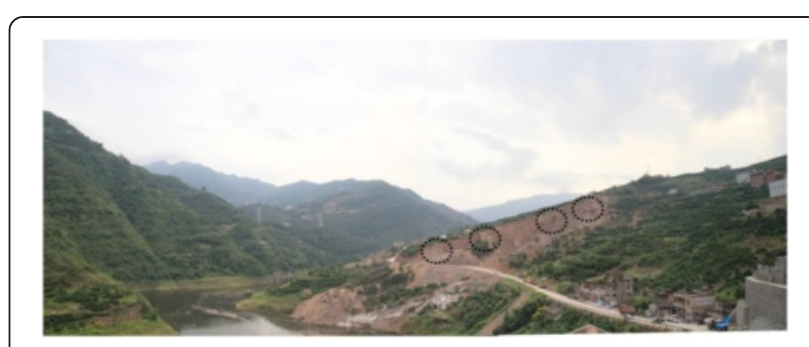

Fig. 13 Lateral view of the Shanshucao Landslide (taken on Sep. 12, 2014). The cliff is the northern flank cliff of the landslide. Black dotted lines are damaged parts of the rock bridge (fresh exposures) 

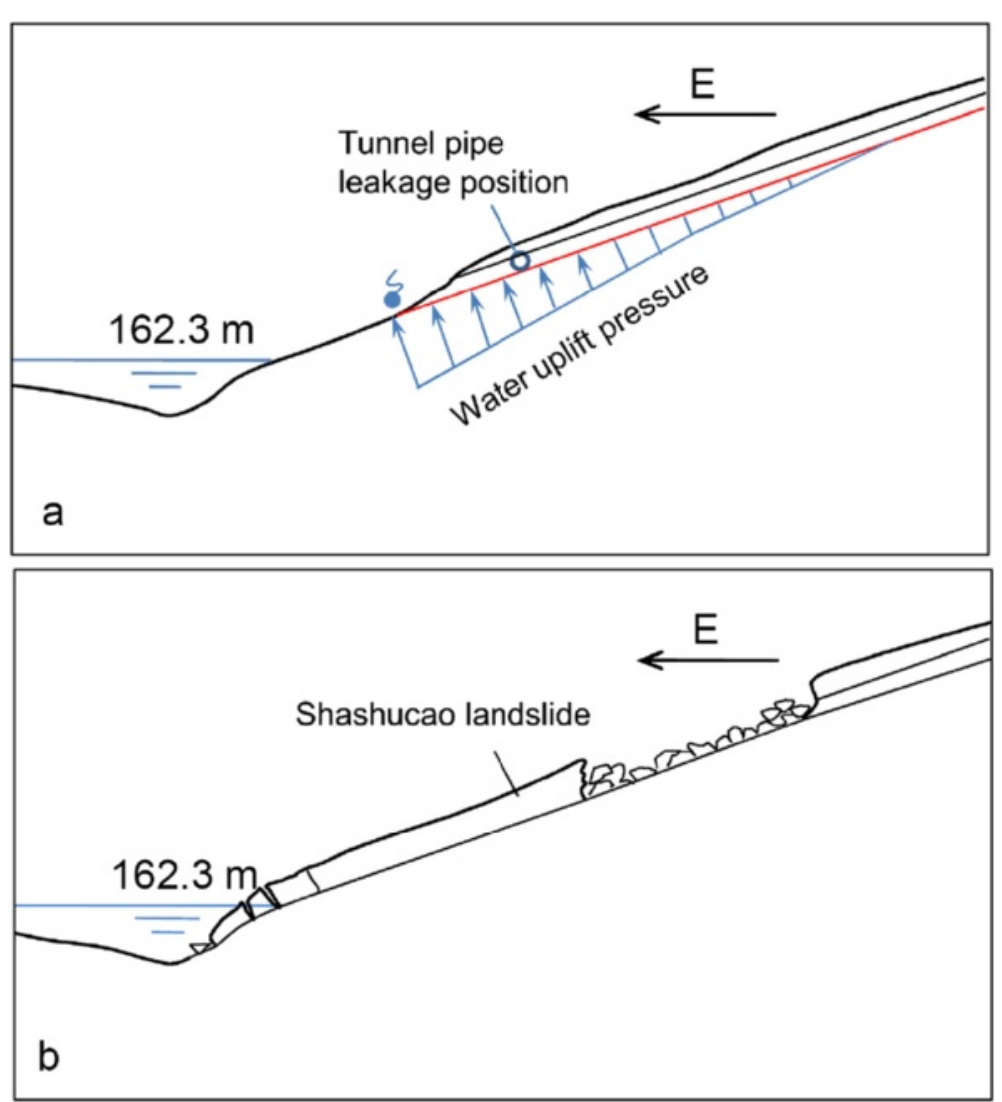

Fig. 14 Schematic diagram of the mechanical model (a) before the landslide and (b) after the landslide

slope was deforming rapidly and had the tendency to fail. Under these conditions, an official decision was needed to deal with the emergency, without delay. If routine practice had been followed, by first ascertaining the scale and extent of landslide, and then making the official decision, action would have been delayed, and casualties would almost certainly have resulted.

An early official evacuation decision was also made before the Qianjiangping landslide (Fig. 1), which occurred in July 13th, 2003. Between June 27th and July 4th of that year, fissures appeared in the crown and the middle part of the Qiangjiangping landslide. In these eight days, the relative displacement of the fissure reached about $4 \sim 6 \mathrm{~cm}$. The official decision of evacuation was at 21:40 p.m in 12th, 2003, when the ground of the front platform of the Qianjiangping landslide began to bulge, and loud underground noises could be heard.

In neither of these two landslides was any professional monitoring work carried out before they failed. These two official evacuation decisions were made based on qualitative judgements of the imminent potential for landslide. These judgements depended on the experience of the engineering geologists who were on-site. If professional monitoring data is available, observation of the acceleration of deformation can be used to quantitatively evaluate the potential for landslide. An example of the use of such data is given by the Wangxia rockmass which is located in the Wu Gorges of the Three Gorges Reservior. Acceleration of deformation was detected by monitoring on 21st Oct, 2010, This data helped in the successful issuing of a warning before mass movement occurred.

In short, most official evacuation decisions depend on informed judgments from engineering geologists, on the potential for imminent failure of landslides.

\section{Conclusions}

A detailed field investigation was made of the Shanshucao landslide that occurred on Sept. 2, 2014, in the Three Gorges Reservoir. The process and the mechanism of the landslide, the factors affecting slope failure, and especially the emergency evacuation procedure were examined. Based on fieldwork and analyses, the following conclusions were reached:

1. Shanshucao landslide is a bedding landslide with a volume of $465,000 \mathrm{~m}^{3}$. The translational slide of the rocky mass led the lateral soil mass to slide rotationally on the surface of rupture. The southern 
flank boundary of the rocky mass was a pre-existing structural plane.

2. Intense rain and rapid raise of water level led the Shashucao landslide to deform slowly. Leakage of tunnel pipelines produced a high uplift pressure, which was the key trigger of the slide.

3. The keys to the successful emergency evacuation of the Shanshucao landslide lie in timely reports by the local people, and collaborative decisions made by landslide specialists and government officials. This landslide crisis was solved successfully by the MEWNG system that operates in the Three Gorges Reservoir.

4. Establishment of warning systems similar to MEWNG is recommended for geological disaster-prone areas around the world.

\section{Competing interests}

The authors declare that they have no competing interests.

\section{Authors' contributions}

Bolin Huang and Zuzhan Yu chose the research direction of this paper, Zuzhan Yu and Wangjun Zheng collected informations of this landslide before and during failure. Bolin Huang and Guangning Liu carried out the emergency survey after failure, and drafted the manuscript. Both authors read and approved the final manuscript.

\section{Acknowledgements}

This work was supported by the National Natural Science Foundation of China (ID: 41372321), and the China Geological Survey Geo-hazard project (ID: 12120114079301). The authors would like to thank Prof. Barry Roser and Prof. Wang Fawu which made great effort to improve this paper, and also several anonymous reviewers are appreciated.

\section{Author details}

'Wuhan Centre of China Geological Survey, Wuhan 430205, China.

${ }^{2}$ Geological Environment Monitoring Station of Zigui County, Zigui 443600,

China.

Received: 22 December 2014 Accepted: 10 July 2015

Published online: 28 July 2015

\section{References}

Brönnimann CS (2011) Effect of Groundwater on Landslide Triggering. The thesis for Ph.D. Laboratory of Engineering and Environmental Geology, EPF Lausanne, Switzerland

Fan X, Xu Q, Zhang Z, Meng D, Tang R (2009) The genetic mechanism of a translational landslide. Bulletin of Engineering Geology and the Environment 68(2):231-244

He K, Wang S, Du W, Wang S (2009) Dynamic features and effects of rainfall on landslides in the Three Gorges Reservoir region, China: using the Xintan landslide and the large Huangya landslide as the examples. Environmental Earth Sciences 59(6):1267-1274

Le Q, Wang H, Xue X, Gao Y, Jin X, Zhang J, Pan S (2011) Deformation monitoring and failure mechanism of wangxia dangerous rock mass in wushan county. Chinese Journal of Engineering Geology 19(6):823-831

Li L (2000) The construction on geological disaster pre-warning system with the Chinese characteristics. Geology in China 4:6-8

Li L (2002) Landslide's prevention and control in the Yangtze gorges reservoir area in China. Land \& Resource 4:4-7

Luo P (1986) The deformation and emergency forecasting on Xintan landslide. Chinese Bulletin of Soil and Water Conservation 4:40-45

Miller S, Brewer T, Harris N (2009) Rainfall thresholding and susceptibility assessment of rainfall-induced landslides: application to landslide management in St Thomas, Jamaica. Bulletin of Engineering Geology and the Environment 68(4):539-550
Singh Y, Bhat GM, Sharma V, Pandita SK, Thakur KK (2012) Reservoir induced landslide at Assar, Jammu and Kashmir: a case study. Journal Geological Society of India 80:435-439

Wang S (1996) Review on prediction of Xintan landslide. The Chinese Journal of Geological Hazard and Control 7(S):11-19

Wang FW, Zhang Y, Huo ZT, Tatsunori M, Huang BL (2004) The July 14, 2003 Qianjiangping landslide, Three Gorges Reservoir, China. Landslides 1:157-162

\section{Submit your manuscript to a SpringerOpen ${ }^{\circ}$ journal and benefit from:}

- Convenient online submission

- Rigorous peer review

- Immediate publication on acceptance

- Open access: articles freely available online

- High visibility within the field

- Retaining the copyright to your article

Submit your next manuscript at $\gg$ springeropen.com 